\title{
REGLAMENTACIÓN ACTO COOPERATIVO - USO INDEBIDO DE PRERROGATIVAS OTORGADAS POR LA LEY A ENTIDADES DE ECONOMÍA SOLIDARIA
}

\author{
Fecha de Recibido: 26 de marzo de 2012 \\ Fecha de aprobación: 6 de junio de 2012 \\ Artículo resultado de investigación.
}

Angelita Linda Mosquera Barraza*

\begin{abstract}
Resumen
Las cooperativas son personas jurídicas que pueden realizar contratos, comparecer en juicio y actuar en todo aquello que esté conforme con su índole social y económica. Sus actos son de comercio en la forma, pero no en la esencia, por no existir el lucro, por no reunir todas sus características formales.
\end{abstract}

Se distinguen entre actos internos y externos. Los primeros son los celebrados entre los asociados y la cooperativa; los segundos, los celebrados con terceros no asociados, pero para beneficio de sus asociados, o mejor dicho, para poder cumplir el fin social. Lo que se pretende en reconocer el espíritu del cooperativismo, lo que conduce al punto central de este trabajo: "El acto cooperativo" desde la perspectiva de su reglamentación.

Las organizaciones de la economía solidaria, han sido creadas, como su nombre lo indica, con el espíritu de protección hacia los más necesitados, ofreciendo servicios de mayor acceso a las poblaciones más vulnerables; pero esto se ha desvirtuado por estas entidades al aprobar créditos desconociendo algunos de los derechos y a su vez excediendo los límites de sus actuaciones, al usar las prerrogativas otorgadas por la ley y realizar embargo de pensiones y salarios de personas que no son asociados o que no ejercen sus derechos como tal, lo que constatamos con el mayor número de quejas que presentan los usuarios en la Superintendencia de la Economía Solidaria por el tema de Usura y otras irregularidades en el otorgamiento y cobro de créditos.

Se sugiere entonces la reglamentación del acto cooperativo dentro de nuestra legislación colombiana a través de una Ley, Decreto o norma imperativa que le de fuerza o herramientas a los colombianos y a las entidades de control para actuar en contra de los administradores o entidades solidarias que cometen este tipo de actuaciones contrarias a derecho.

Es claro ver la profunda importancia del tema propuesto, dado que el cooperativismo y la economía solidaria son objeto de una regulación legal cada vez más amplia en nuestro país por la importancia y la forma como afecta las decisiones a nivel nacional en lo laboral y otro muchos aspectos que inicialmente se desarrollaron sin ningún marco

\footnotetext{
Abogada, Especialista en Derecho Administrativo, Universidad la Gran Colombia. Técnico Administrativo, Delegatura para la Supervisión del Ahorro y la forma Asociativa Solidaria Superintendencia de la Economía Solidaria. Correo electrónico: amosbarraza@gmail.com
} 
normativo, como es el caso de varias de las formas asociativas que fueron ideadas para solucionar problemas económicos, sociales, culturales y ambientales, terminaron por ser reglamentados jurídicamente (Sarmiento \& Guarín, 1999).

\title{
Palabras Clave
}

Acto Cooperativo, asociados, ánimo de lucro, entidad solidaria, créditos.

\section{COOPERATIVE REGULATION ACT - INAPPROPRIATE USE OF PRIVILEGES GRANTED BY LAW SOLIDARITY ORGANIZATIONS}

\begin{abstract}
The cooperatives are legal entities which may make contracts, appear in trial and act on everything that is in accordance whit its social and economic nature. These acts are from trade on the form, but not in the essence, because in the cooperatives don't exist the profit, the trade act haven't all its form characteristics.
\end{abstract}

It differs between internal and external acts. The first one is celebrating between the members and the cooperative; the second, the celebrating with third no members, but for benefic of its members, or rather, to comply the social goal.

What is intended to recognize the spirit of cooperation, leading to the central point of this work: "The cooperative act" from the viewpoint of its rules.

The organizations of the solidarity economy, have been created, as the name implies, with the spirit to protect to the most neediest, providing more access to the most vulnerable populations; but this has been disproved by these institutions to approve loans without knowing some of the rights and in turn stretch the limits of her performances, using the powers granted by law and perform sequestration pensions and salaries of persons who are not partners or who do not exercise their rights as such that we find the largest number of complaints that users on the Superintendencia de la Economía Solodaria for the issue of usury and other irregularities in the granting and debt recovery.

It then suggests the regulation of cooperative action within our Colombian law through a law, decree or mandatory rule that force or tools to Colombians and control agencies to act against the administrators or solidarity organizations that make this type of acts against law.

It is suggested that regulation of the cooperative act within the Colombian legislation through a law, decree or mandatory rule that gives strength or tools to Colombians and control agencies to act against the administrators or solidarity organizations who commit this type of acts against law.

It is clear to see the profound importance of the proposed topic, as the cooperative and solidarity economy are the object of legal regulation widening in our country for the importance and how it affects decisions at national level in terms of work and a lot other aspects that initially developed without any regulatory framework, as is the case with 
several of the forms of association that were designed to solve economic, social, cultural and environmental eventually be regulated legally (Sarmiento \& Guarín, 1999).

\title{
Keywords
}

The Cooperative Act, Members, Profit, solidarity organizations, credits.

\section{REGULAMENTO ATO COOPERATIVO. USO IMPRÓPRIO DE PRERROGATIVAS CONCEDIDAS POR A LEI PARA ENTIDADES DE ECONOMIA SOLIDÁRIA}

\begin{abstract}
Resumo
As cooperativas são entidades jurídicas que podem fazer contratos, o seu julgamento e agir em tudo o que você está satisfeito com a sua natureza social e econômica. Suas ações são negociadas em forma, mas não a essência, porque não há lucro, não satisfazer todas as suas características formais.
\end{abstract}

Ela difere entre os atos internos e externos. O primeiro está comemorando entre os membros da cooperativa e, a segunda, a celebrar com terceiros não membros, mas para benéfico dos seus membros, ou melhor, para cumprir o objetivo social.

As organizações da economia solidária, foram criados, como o nome indica, com o espírito pra proteger aos mais necessitados, proporcionando mais acesso às populações mais vulneráveis, mas isso foi desmentido por estas instituições por aprovar empréstimos sem conhecer alguns dos os direitos e por sua vez, ampliar os limites de suas performances, no uso das atribuições conferidas por lei e executar o sequestro pensões e salários de pessoas que não sejam parceiros ou que não exercer os seus direitos como tal, que encontramos o maior número de reclamações que os usuários em a Superintendência de la Economía Solodaria para a questão da usura e outras irregularidades na concessão e recuperação de dívidas.

Em seguida, sugere a regulamentação da ação cooperativa dentro do nosso direito colombiano através de uma regra lei, decreto ou obrigatório que a força ou as ferramentas para os colombianos e agências de controle para agir contra os administradores ou organizações de solidariedade que fazem este tipo de actos contra a lei.

É claro, para ver a profunda importância do tema proposto, como a economia cooperativa e solidária são objecto de alargamento na regulamentação legal no nosso país por causa da importância e como ela afeta as decisões a nível nacional em termos de trabalho e muito aspectos que, inicialmente, desenvolvidos sem qualquer marco regulatório, como é o caso de várias das formas de associação que foram projetados para resolver econômica, social, cultural e ambiental, eventualmente, ser regulado legalmente (Sarmiento \& Guarín, 1999).

\section{Palavra-chave}

O Ato Cooperativo, membros, de lucro, as organizações de solidariedade, os créditos. 


\section{INTRODUCCIÓN}

Para este trabajo es evidente que al pretender crear una normatividad en relación con el problema económico planteado es necesario acudir a las fuentes materiales que son las necesidades, los problemas prácticos que hacen que surjan las normas jurídicas para lograr la convivencia social.

Dado lo anterior se hace necesario determinar si es procedente el embargo de pensiones o salarios de personas que no son asociadas a las entidades de economía solidaria y que no han realizado ningún acto cooperativo según la Ley 79 de 1988 expedida por el Congreso de Colombia e instruida en las circulares emitidas por la Superintendencia de la Economía Solidaria.

La presente investigación se suscribe a la línea de investigación propuesta por la Universidad La Gran Colombia, Derecho Económico para la Integración Regional como Instrumento del Estado para Regular todas las Actividades como Mecanismo de Intervención; esta se encarga de reglamentar las actividades de los particulares en el plano económico. Lo cual conlleva a determinar la existencia de un derecho económico público y de un derecho económico privado, donde entran en juego los diferentes agentes y actividades económicas que conforman la economía nacional (local y regional) e internacional.

\section{ANTECEDENTES CONSTITUCIONALES, DOCTRINARIOS Y JURISPRUDENCIALES DE LA ECONOMÍA SOLIDARIA Y EL ACTO COOPERATIVO}

La formalización del modelo solidario en Colombia tiene una historia reciente que se inició en 1931 comparada con el modelo inglés que dio vida a este tipo de organizaciones.

En 1844, un grupo de obreros ingleses creó una organización cooperativa de carácter legal, con los aportes de sus integrantes.
El 24 de octubre de 1844 crearon el primer Almacén Cooperativo en la Ciudad de Rochdale, Inglaterra, considerado hoy como el origen de este tipo de entidades (si bien han existido otros intentos anteriores). Estaba formado por 28 tejedores desocupados de la fábrica de tejido de Rochdale, por haber participado de una huelga, y aportaron como capital a la nueva Sociedad la cantidad de 28 peniques cada uno. Hoy son conocidos como "Los Pioneros de Rochdale”. (Bel \& Cabaleiro, 2002).

Es claro que este no es el origen fundacional de este tipo de organizaciones dado que desde mucho antes, en la edad media, se podían ver esbozos de economía similares y que con el pasar del tiempo, los cambios sociales, políticos y culturales generaron el caso de los Pioneros, el cual destacamos por su éxito.

Los Pioneros se auto impusieron reglas que debían respetar rigurosamente y que fueron una de las causas de su éxito. Crearon una carta que establecía los pasos que guiarían a la organización. Así nació el cooperativismo organizado. Sus principios, fundamentados en genuinos ideales de solidaridad, fueron asentados en la "Carta de Cooperación" que Carlos Horteserth, paladín de esta fundación, presentó ante las Cámaras de los Comunes:

La cooperación completa la economía política al organizar la distribución de la riqueza.

- No afecta la fortuna de nadie.

- No trastorna la sociedad.

- No molesta a los hombres del Estado.

- No constituye una asociación secreta.

- No quiere ninguna violencia.

- No causa ningún desorden.

- No ambiciona honores.

- No reclama favores.

- No pide privilegios especiales.

- No trata con holgazanes.

- No busca ayuda oficial. 
En Colombia la Superintendencia de la Economía Solidaria ha instruido a través de circulares a las entidades bajo su supervisión en similar sentido, definiendo los principios y fines de estas, los cuales van dirigidos hacia los mismos objetivos; dentro de los más importantes y que atañe al tema estudiado, se encuentra que se debe tener establecido un vínculo asociativo, la solidaridad y el servicio social o comunitario.

En 1995, el Congreso de la ACI, realizado en Manchester, Inglaterra, aprobó 7 nuevos principios:

- Adhesión voluntaria y abierta.

- Gestión democrática por parte de los asociados.

- Participación económica de los asociados.

- Autonomía e Independencia.

- Educación, formación e información.

- Cooperación entre cooperativas.

- Interés por la comunidad.

En 1923 el Comité Ejecutivo de la Alianza Cooperativa Internacional (ACI) recomendó conmemorar un día internacional de las cooperativas. El 16 de diciembre de 1992 la Asamblea GeneraldelaONU(NacionesUnidas), a través de la resolución 47/90, proclamó la necesidad de realizar un "Día Internacional de las Cooperativas" a partir de julio de 1995, en conmemoración al centenario de la creación de la Alianza Cooperativa Internacional (ACI) (Grupo que reúne organizaciones cooperativas de 100 países que cuentan con un total de 700 millones de miembros).

Se entiende que con este tipo de actividades y reconocimiento se propende por la integración económica y social de sus miembros y por la promoción del desarrollo integral del ser humano a través de estímulos.

La ACI fue fundada en Londres en 1895. El 23 de diciembre de 1994, la Asamblea General de la ONU, por medio de la resolución 49/155, invitó a los gobiernos, organizaciones internacionales, organismos especializados y organizaciones coo- perativas nacionales $e$ internacionales a observar anualmente el "Día Internacional de las Cooperativas", reconociendo que las cooperativas estaban pasando a ser un factor indispensable del desarrollo económico y social. Una de las maneras en que la ONU mostró este reconocimiento fue al declarar, en 1995, que el "Día Internacional de las Cooperativas" debía ser celebrado cada año por los gobiernos en colaboración con sus movimientos cooperativos nacionales. En 1996, al celebrar la comunidad internacional el "Año para la Erradicación de la Pobreza", la ONU, una vez más, atrajo la atención de los gobiernos en cuanto a la considerable contribución de las cooperativas en la reducción de la pobreza y en la necesidad de asociar el movimiento a esta tarea." (Bel \& Cabaleiro; 2002).

De lo anterior se colige que el acto cooperativo surge del desarrollo que ha tenido este tipo de entidades y de la necesidad de crear pautas de cómo diferenciar las relaciones existentes entre las entidades solidarias con sus asociados. Diferenciando este tipo de vínculos de los otros tales como los laborales, comerciales y civiles.

Es por ello que se hace necesario esclarecer que la formalización del modelo solidario en Colombia es de relativa creación que se inició en 1931 con la expedición de la ley 134. En 1986 se adopta el concepto de Economía Solidaria con el decreto 2536 del 4 de agosto que dio vida al Consejo Nacional de Economía Solidaria y lo reconoce como un sector de gran importancia en el entorno económico nacional. Y en 1988 con la ley 79 se organizan las formas solidarias del cooperativismo, asociaciones mutuales y fondos de empleados.

Hasta 1999, la función de supervisión de las entidades de economía solidaria fue adelantada por el Departamento Nacional de Cooperativas -Dancoop-, la institución de gobierno encargada de definir la política para las formas solidarias de organización en particular para el 
sector cooperativo. La entidad tenía a su cargo la planificación de sus políticas, la ejecución de programas y proyectos y a su vez, el ejercicio del control de gestión de las mismas.

En esa perspectiva, se evidenció un importante desarrollo de entidades; sin embargo, la falta de un marco regulatorio propició la informalidad de la actividad solidaria. Se abrió un gran espacio para la incorporación y canalización de recursos emergentes, y formas indebidas de manejo de recursos, conllevando a una crisis que afectó al sistema financiero nacional.

Como respuesta a la crisis del sector financiero y su reflejo en las organizaciones solidarias, el Gobierno del Presidente Ernesto Samper Pizano expidió la Ley 454 de 1998, que transformó al Departamento Nacional de Cooperativas -Dancoop- en el Departamento Administrativo de la Economía Solidaria -Dansocial-; y creó a la Superintendencia de la Economía Solidaria -Supersolidaria- y al Fondo de Garantías del Sector Cooperativo -Fogacoop.

El doctor Juan Camilo Restrepo, en ese entonces Ministro de Hacienda expresó:

"Necesitamos una entidad ágil y eficiente, que rescate el sector solidario de Colombia".

A la luz de la ley 454 del 98, se denomina Economía Solidaria al sistema socioeconómico, cultural y ambiental conformado por el conjunto de fuerzas sociales organizadas, en formas asociativas identificadas por prácticas autogestionadas solidarias, democráticas y humanistas, sin ánimo de lucro para el desarrollo integral del ser humano como sujeto, actor y fin de la economía.

Esta estructura estatal significó el retorno de la confianza en el sector solidario, especialmente en la actividad financiera, al que se le establecieron definiciones, alcances y condiciones claras para su ejercicio. (Supersolidaria, 2011).

Una vez promulgada la Constitución Política, el Derecho Cooperativo Colombiano ha logrado importantes desarrollos sobre todo a partir de los aportes doctrinales y jurisprudenciales de las Cortes. Donde sobresalen los conceptos de la Corte Constitucional, centrándose en aspectos tales como el acuerdo cooperativo, el acto cooperativo, la actividad no lucrativa y las diferencias con el acto comercial. Así mismo se ha incursionado en estudios sobre la libertad de asociación y el ejercicio de la democracia cooperativa.

Como base de este trabajo se tiene el Artículo 333. de la Constitución Nacional, que al tenor dice:

"Iniciativa privada y libertad de empresa. La actividad económica y de iniciativa privada son libres, dentro de los límites del bien común. Para su ejercicio, nadie podrá exigir permisos previos ni requisitos sin autorización de la ley. La libre competencia económica es un derecho de todos que presupone responsabilidades.

La empresa, como base del desarrollo, tiene una función social que implica obligaciones. El Estado fortalecerá las organizaciones solidarias y estimulará el desarrollo empresarial.

El Estado, por mandato de la ley, impedirá que se obstruya o se restrinja la libertad económica y evitará o controlará cualquier abuso que persona o empresa hagan de su posición dominante en el mercado nacional.

La ley delimitará el alcance de la libertad económica cuando así lo exijan el interés social, el ambiente y el patrimonio cultural de la Nación."

Mencionado lo anterior es claro que el Estado debe promover esta forma de desarrollo empresarial. Por ello, es necesario que las reglas del juego queden claras, para con ello evitar que se desnaturalice el objeto social de este tipo de organizaciones y no se pierda la confianza en el sector.

Está estrechamente vinculado al nacimiento $\mathrm{u}$ origen del acto cooperativo como fuente principal 
de su creación y encausado a lograr determinar se así como antes se mantienen los ideales de solidaridad y ayuda mutua con el apoyo de organismos internacionales y la aplicación a través de las distintas entidades gubernamentales de los principios y normatividad vigente que permita un mayor desarrollo del sector solidario y aplicación correcta de su filosofía.

Como se ha venido explicando la formalización del modelo de la economía solidaria en nuestro país es relativamente nueva con la expedición de la Ley 134. Posterior a ella en 1986 se adopta el concepto de Economía Solidaria con el decreto 2536 del 4 de agosto que dio vida al Consejo Nacional de Economía Solidaria y lo reconoce como un sector de gran importancia en el entorno económico nacional.

En 1988 con la ley 79 se organizan las formas solidarias del cooperativismo, asociaciones mutuales y fondos de empleados.

Hasta 1999, la función de supervisión de las entidades de economía solidaria fue adelantada por el Departamento Nacional de Cooperativas -Dancoop-, la institución de gobierno encargada de definir la política para las formas solidarias de organización en particular para el sector cooperativo.

Como consecuencia de las necesidades del desarrollo social y normativo fue creada la Superintendencia de la Economía Solidaria cono ente regulador de este sector en crecimiento.

Teniendo en cuenta las sentencias de la Corte Constitucional, los pronunciamientos del Consejo de Estado y las posiciones de algunos autores sobre el tema en estudio, se puede ver que hay diversas corrientes en las que se evidencian teorías opuestas.

Siguiendo el marco normativo, la Ley 79 de 1988 que define el "acto cooperativo" en el artículo $7^{\circ}$. Serán actos cooperativos los realizados entre sí por las cooperativas, o entre éstas y sus propios asociados, en desarrollo de su objeto social, tenemos los fundamentos de la demanda de la Sentencia No. C-589/95 en la que en opinión del demandante las expresiones acusadas de los artículos 3, 4 y 10 de la Ley 79 de 1988, "Por la cual se actualiza la legislación cooperativa", y del artículo 156 de la Ley 141 de 1961, Código Sustantivo del Trabajo, vulneran y son contrarias a los principios de vigencia de un orden justo y de igualdad ante la ley que consagran los artículos 2 y 13 de la Constitución Nacional.

Manifiesta el actor que las normas demandadas, al definir las cooperativas como personas jurídicas sin ánimo de lucro, cuyas actividades deben estar orientadas a satisfacer las necesidades de sus asociados y de la comunidad en general, están desconociendo la "realidad material" de dichas entidades, que como cualquier empresa requieren, para crecer y fortalecerse, del lucro que se genere de sus actividades y transacciones, entendiendo por lucro el "beneficio o provecho que se obtiene de algo". Lo contrario, señala, sería tanto como imponerles el trabajar a pérdida, dejando en entredicho el desarrollo mismo del sistema cooperativo.

Ese lucro, que requieren las cooperativas para fortalecerse y ampliarse, puede obtenerse, en opinión del demandante, de los "excedentes" que se originen en actividades y transacciones que se desarrollen con terceros no asociados, teniendo en cuenta que, precisamente, el artículo 10 de la Ley 79 de 1988, autorizó a las cooperativas a "extender sus servicios" al público no afiliado, sin que por ello se desvirtúe el objetivo que les es propio de propender por el beneficio colectivo y el interés social y público.

Distingue el demandante, con fundamento en el artículo 7 de la Ley 79 de 1988, entre el "acto cooperativo", que se realiza entre cooperativas o entre éstas y sus asociados, y el "acto mercantil", que surge de las relaciones entre la cooperativa y un no afiliado; éste último, señala, debe estar regulado por el Código de Comercio, artículos 20, 21 y 22 y debe someterse a sus disposiciones, pues ellos están “...investidos verdaderamente de ánimo 
lucrativo y mercantilista..." y no corresponden en sus características a los principios y doctrinas que rigen el sistema cooperativo.

Con base en esta distinción, el actor encuentra injustificada e inconstitucional la disposición del artículo 10 de la ley 79 de 1988, que se refiere a que los excedentes obtenidos en las cooperativas, por el desarrollo de actividades o transacciones con personas no afiliadas, con terceros, deben ser llevados a un fondo social no susceptible de repartición, pues, reitera, los mismos se originan en transacciones del "más puro corte mercantilista" y en ellos subyace un claro ánimo de lucro y especulación; reclama entonces para esos excedentes, que sostiene, son en estricto sentido lucro, la aplicación del principio de participación en las utilidades obtenidas, por tratarse de actos mercantiles que como tales deben someterse a la normatividad del Código de Comercio, pues de lo contrario se incurriría en la violación al principio de igualdad ante la ley que consagra el artículo 13 de la C.P.

Con fundamento en lo expresado por esta Corporación, en el sentido de que "...la ausencia de ánimo de lucro se predica de las personas que son miembros de una asociación o corporación, pero no de esta en sí misma considerada...", (Sentencia C-051 de febrero de 1995, M.P. Dr. Jorge Arango Mejía), el actor afirma que la ausencia de ánimo de lucro a que se refieren los artículos 3 y 4 de la ley 79 de 1988, normas que contienen las expresiones demandadas, solo "...podría predicarse de los cooperados o socios de la cooperativa, más no de los actos resultantes de la extensión al público no afiliado de los "servicios" de la cooperativa, en desarrollo de su objeto social, que, señala, constituirían actos no cooperativos, en su criterio, actos mercantiles.

Enfatiza el actor el presunto desconocimiento que las normas impugnadas hacen de la "realidad material", anotando que cuando ello ocurre "se entronizan desigualdades, privilegios y discriminaciones irrazonables", que conducen a quebrantar el principio de igualdad ante la ley a que se refiere el artículo 13 de la Carta; destaca en este punto pronunciamientos de la Corte Constitucional en el sentido de que la aplicación de un tratamiento jurídico diferente a situaciones materialmente semejantes, sólo se justifica cuando es indispensable para mantener condiciones de igualdad básica de oportunidades, de lo contrario genera el reconocimiento de un privilegio y la consecuente discriminación.

Por último, también cuestiona algunas expresiones del artículo 156 de C.S. del T., por considerar, que al igual que aquellas acusadas de la ley 79 de 1988, su contenido vulnera el principio de igualdad ante la ley, pues al viabilizar la posibilidad de embargo a favor de las cooperativas legalmente establecidas, hasta del $50 \%$ del salario de un trabajador, sin distinguir si las obligaciones provienen de un "acto cooperativo" o de un "acto mercantil", está autorizando, en lo que se refiere a estos últimos, la aplicación de un tratamiento discriminatorio para los comerciantes, lo cuales no pueden solicitar embargos por sumas superiores a la quinta parte de lo que exceda el salario mínimo legal mensual del trabajador.

Dentro de la oportunidad correspondiente, se hizo presente la abogada Aidy Lucia Medina Cordero, quien como apoderada y representante del Departamento Administrativo Nacional de Cooperativas, manifestó su intención de defender la constitucionalidad de las disposiciones impugnadas, para lo cual presentó a consideración de esta Corporación los siguientes argumentos:

En primer lugar, la interviniente consideró pertinente distinguir el acto comercial del acto cooperativo; el primero, señala, además de caracterizarse por estar referido a conductas reiteradas del comerciante que constituyen su medio normal de vida, está regido por el Código de Comercio como norma especial y sólo en aquello que dicho estatuto no regule de manera específica, le serán aplicables las normas supletorias contenidas en el Código Civil. 
Para referirse al segundo, al acto cooperativo, la interviniente se remite a la doctrina: "...el acto cooperativo es el supuesto jurídico, ausente de lucro y de intermediación, que realiza la organización cooperativa en cumplimiento de un fin preponderantemente económico y de utilidad social."

"El acto cooperativo se constituirá en 'fuente' de la relación jurídica cooperativa, tiene un evidente contenido subjetivo, ya que exige en todos los casos la concurrencia de la cooperativa como uno de sus sujetos, pudiendo el otro sujeto ser otra cooperativa o un asociado, e incluso un tercero no asociado, pero en todos los casos el acto estará dirigido al cumplimiento del objeto social de la cooperativa, el bienestar de la comunidad y la consecución de sus fines institucionales."(La interviniente cita a Corbella, Carlos Jorge, Los actos Cooperativos. Apuntes para un Estudio Metodológico. Intercoop, Editora Cooperativa Ltda., 1985, Buenos Aires, Argentina.)

Destaca cómo el sistema cooperativo está ligado de manera estrecha a la búsqueda del bienestar de la comunidad, principio que subyace en el texto de las normas que definen el objeto y características del mismo, contenidas en la Ley 79 de 1988, especialmente en sus artículos 2, 3 y 4. Así, anota, en el artículo 3 de manera explícita se consigna como principio esencial de las cooperativas, la ausencia de ánimo de lucro en las actividades que éstas cumplan, en las que debe prevalecer como objetivo principal el interés social.

Se refiere al concepto de empresa aclarando que este admite diferentes formas organizativas: empresa capitalista, pública o cooperativa, todas ellas, anota, deben ser autosuficientes, "...pues no se trata de vender los bienes o servicios por debajo del costo...", la distinción se ubica en la connotación que en unas y otras dan a la diferencia entre el costo de un bien o un servicio y el precio de venta del mismo; en la empresa capitalista dicha diferencia constituye lucro, entendido como ganancia, provecho o utilidad, mientras en la empresa cooperativa esa diferencia constituye el excedente, que precisamente se caracteriza por no ser objeto de distribución entre los asociados, en proporción a sus aportes, y por estar su destinación predeterminada en la misma ley, que como lo señalaba también el Ministerio Público, establece de manera expresa las actividades que se pueden financiar con ellos, medida con la que se garantiza el cumplimiento del objetivo esencial del sistema: el beneficio social.

El sistema cooperativo desde sus orígenes en la Rochdale Society of Equivale Pioneers, constituida en 1844 en Inglaterra, se apoya en un principio esencial, que define su propia naturaleza y que hoy se acepta universalmente: la realización de su objeto social prescindiendo del ánimo de lucro. Dicho principio lo adoptó la legislación colombiana y actualmente se encuentra consagrado en la Ley 79 de 1988, "Por la cual se actualiza la legislación cooperativa", norma que en su artículo 4 define este tipo de organización de la siguiente manera:

"Es cooperativa la empresa asociativa sin ánimo de lucro, en la cual los trabajadores o los usuarios, según el caso, son simultáneamente los aportantes y los gestores de la empresa creada con el objeto de producir o distribuir conjunta y eficientemente bienes o servicios para satisfacer las necesidades de sus asociados y de la comunidad en general."

En concepto del actor es innegable que las cooperativas desarrollan actos mercantiles, necesarios para su propia existencia como empresas privadas, las cuales requieren de la generación de lucro para garantizar su funcionamiento y permanencia; dichos actos, en tanto actos mercantiles, señala el demandante, deben estar excluidos de los condicionamientos y restricciones a los que están sometidos aquellos actos que si reúnen las condiciones necesarias para ser calificados como actos cooperativos. En consecuencia, reclama para los que califica actos mercantiles, la aplicación de la legislación comercial vigente, pues considera que al someterlos a la legislación cooperativa se están contrariando los principios de vigencia 
de un orden justo y de igualdad ante la ley, consagrados en los artículo 2 y 13 de la Carta.

En Colombia el Constituyente de 1991, en el ya citado artículo 58 de la C.N., no sólo concedió un carácter especial y preferencial a las distintas formas de economía solidaria, al consagrar que "El Estado protegerá y promoverá las formas asociativas y solidarias de propiedad", sino que atribuyó a los poderes públicos una responsabilidad específica para el efecto. Sobre el particular ha dicho esta Corporación:

Las cooperativas, como personas jurídicas de derecho privado, realizan, en cumplimiento de su objeto social, multiplicidad de actos jurídicos; sin embargo, no todos esos actos pueden calificarse como actos cooperativos, pues ellos están definidos expresamente en el artículo 7 de la Ley 79 de 1988:

“artículo 7o.- Serán actos cooperativos los realizados entresípor las cooperativas, o entre éstas y sus propios asociados, en desarrollo de su objeto social."

Otros actos los realiza la cooperativa con terceros no afiliados en cumplimiento de su objeto social; en ambos casos pueden producirse, como de hecho se producen, actos comerciales, sin que con ello se desvirtúe o contraríe el objeto social de dichas empresas, o se vulnere disposición superior alguna. Así lo establece el artículo 10 de la ley 79 de 1988:

"Artículo 10. Las cooperativas prestarán preferencialmente sus servicios al personal asociado. Sin embargo, de acuerdo con sus estatutos, podrán extenderlos al público no afiliado, siempre en razón del interés social o del bienestar colectivo. En tales casos, los excedentes que se obtengan serán llevados a un fondo social no susceptible de repartición."

El destino que señala la norma citada para los excedentes obtenidos por el desarrollo de operaciones con terceros no afiliados, las cuales pueden ser de naturaleza mercantil, desde ningún punto de vista puede considerarse contrario a las disposiciones del ordenamiento superior, pues tal previsión se ajusta en todo al objeto esencial de las cooperativas, en tanto organizaciones solidarias que propenden por el interés de sus asociados.

A lo anterior la Corte se pronunció declarando exequible los artículos demandados sustentado en que no se desvirtúa el objeto de este tipo de entidades al prestar servicios a terceros y crear "excedentes" que como la norma lo dice luego deben ser repartidos entre sus asociados pero que dichos actos con terceros son mercantiles y se deben regir por las disposiciones del derecho comercial.

\section{Concepto de acto cooperativo}

LEY 79 DE 1988: Por la cual se actualiza la legislación cooperativa, cuyo propósito es dotar al sector cooperativo de un marco propicio para su desarrollo como parte fundamental de la economía nacional. En relación con el punto que nos interesa la Ley 79/88 en su artículo $7^{\circ}$. Consagra: "Serán actos cooperativos los realizados entre sí por las cooperativas, o entre éstas y sus propios asociados, en desarrollo de su objeto social".

En su Artículo 19. Los estatutos de toda cooperativa deberán contener:

“(..)

5. Procedimientos para resolver diferencias o conflictos transigibles entre los asociados o entre éstos y la cooperativa, por causa o con ocasión de actos cooperativos.

(...)"

La noción de acto cooperativo surgió en la doctrina cooperativa, principalmente para deslindar los actos jurídicos de la organización cooperativa de los actos jurídicos de las sociedades comerciales y 
civiles. Más adelante tomaría importancia la idea de extender las distinciones respecto de los actos jurídicos que caracterizan las relaciones laborales. En todo caso, este movimiento efectivamente permitió el avance de la especialización del derecho cooperativo, que algunos critican y desconocen.

Para Sergio Reyes, secretario de la Confederación Uruguaya de Entidades Cooperativas, Cudecoop, la identidad del derecho cooperativo se fundamenta en el acto cooperativo, que define como una realidad concreta consistente en el negocio jurídico por medio del cual se ejerce la actividad cooperativa.

En ese mismo sentido Carlos Uribe Garzón afirma lo siguiente: Es comprensible que si las cooperativas forman parte de un sistema económico y social que se aparta en su naturaleza y en muchos de sus procedimientos de otros sistemas, las expresiones jurídicas de sus actividades deban destacar, en los términos del derecho, las características que constituyen su especificidad. (Uribe; 2005).

Alrededor de estas percepciones de carácter jurídico se ha edificado una teoría general del acto cooperativo. La teoría del acto cooperativo, fundada en 1954 por Antonio Salinas Puentes, en su magistral obra, Derecho cooperativo, escrita con especialísimo énfasis en esta institución jurídica, propone la siguiente definición:

"El acto cooperativo es el supuesto jurídico, ausente de lucro y de intermediación, que realiza la organización cooperativa en cumplimiento de un fin preponderantemente económico y de utilidad social" (Salinas; 1954)

La Constitución Política de Colombia contempla y reconoce dentro de su marco jurídico, democrático y participativo-como se menciona dentro del preámbulo de la Constitución- la asociación como un derecho "social" y como una forma de organización del pueblo para interactuar con el Estado y viceversa.

El acto de considerar a Colombia como un Estado Social de Derecho y para ser coherente con estas palabras; la Constitución contempla la asociación de sus ciudadanos en diversas formas y maneras, así mismo establece sus deberes como Estado frente a estas garantizando su organización, promoción y capacitación -como se menciona en el articulo 103-.

Por esta razón la Constitución corresponde al primer marco regulatorio de las formas de asociación y que de ahí parte la importancia del "derecho de asociación" que obliga al Estado a crear una estructura de leyes y entidades que se encarguen de cumplir $y$ hacer cumplir las obligaciones mutuas entre el Estado y las Asociaciones.

Artículos que hacen referencia:

"Artículo 1. Colombia es un Estado social de derecho, organizado en forma de República unitaria, descentralizada, con autonomía de sus entidades territoriales, democrática, participativa y pluralista, fundada en el respeto de la dignidad humana, en el trabajo y la solidaridad de las personas que la integran y en la prevalencia del interés general.

Artículo 51. Todos los colombianos tienen derecho a vivienda digna. El Estado fijará las condiciones necesarias para hacer efectivo este derecho y promoverá planes de vivienda de interés social, sistemas adecuados de financiación a largo plazo y formas asociativas de ejecución de estos programas de vivienda.

Artículo 57. La Ley podrá establecer los estímulos y medios para que los trabajadores participen en la gestión de las empresas.

Artículo 58. Se garantizan la propiedad privada y los demás derechos adquiridos con 
arreglo a las leyes civiles, los cuales no pueden ser desconocidos ni vulnerados por leyes posteriores. Cuando de la aplicación de una ley expedida por motivo de utilidad pública o interés social, resultaren en conflicto los derechos de los particulares con la necesidad por ella reconocida, el interés privado deberá ceder al interés público o social. La propiedad es una función social que implica obligaciones. Como tal, le es inherente una función ecológica. El Estado protegerá y promoverá las formas asociativas y solidarias de propiedad. Por motivos de utilidad pública o de interés social definidos por el legislador, podrá haber expropiación mediante sentencia judicial $e$ indemnización previa. Esta se fijará consultando los intereses de la comunidad y del afectado. En los casos que determine el legislador, dicha expropiación podrá adelantarse por vía administrativa, sujeta a posterior acción contenciosa administrativa, incluso respecto del precio. Con todo, el legislador, por razones de equidad, podrá determinar los casos en que no haya lugar al pago de indemnización, mediante el voto favorable de la mayoría absoluta de los miembros de una y otra Cámara. Las razones de equidad, así como los motivos de utilidad pública o de interés social, invocados por el legislador, no serán controvertibles judicialmente.

Artículo 333. La actividad económica y la iniciativa privada son libres, dentro de los límites del bien común. Para su ejercicio, nadie podrá exigir permisos previos ni requisitos, sin autorización de la ley. La libre competencia económica es un derecho de todos que supone responsabilidades.

La empresa, como base del desarrollo, tiene una función social que implica obligaciones. El Estado fortalecerá las organizaciones solidarias y estimulará el desarrollo empresarial. El Estado, por mandato de la ley, impedirá que se obstruya o se restrinja la libertad económica y evitará o controlará cualquier abuso que personas o empresas hagan de su posición dominante en el mercado nacional.
La ley delimitará el alcance de la libertad económica cuando así lo exijan el interés social, el ambiente y el patrimonio cultural de la Nación.

Además del sustento constitucional anterior tenemos el marco jurídico vigente en Colombia para las cooperativas y demás organizaciones del sector de la economía solidaria:

Ley79de1988. - Marcogeneral del cooperativismo.

Superó un largo periodo de 25 años de vigencia del Decreto Ley 1598 de 1963.

\section{Decretos leyes reglamentarios.}

1333 de 1989 - Establece el régimen de constitución, reconocimiento y funcionamiento de las Precooperativas.

1480 de 1989 - Determina la naturaleza, características, constitución, régimen de responsabilidad y sanciones, y normas para el fomento de las Asociaciones Mutualistas.

1481 de 1989 - Determina la naturaleza, características, constitución, régimen de responsabilidad y sanciones, y normas para el fomento de los Fondos de Empleados.

Decreto ley 2150 de 1995.- Simplifica trámites. Registro en Cámaras de comercio.

Ley 454 de 1998. - Marco conceptual de la economía solidaria. Transforma el Dancoop (Departamento Nacional de Cooperativas) en Dansocial (Departamento Administrativo Nacional de la Economía Solidaria). Crea la SES (Superintendencia de Economía Solidaria). Todas estas con funciones de vigilancia, inspección y control, por lo cual fue necesario crear la Supersolidaria y dejar a Dansocial la función de dirigir y coordinar la política estatal para la promoción, planeación, protección, fortalecimiento y desarrollo empresarial de las organizaciones de la Economía Solidaria. 
Circular Básica Jurídica No. 007 de 2008.

Circular Básica Contable y Financiera No. 004 de 2008. Sobre el particular, Dante Cracogna, consultor de la Alianza Cooperativa Internacional, manifiesta: "La ley 79 de 1988 fue una ley que en su momento fue de avanzada para Colombia $e$ incluso para la región; pero posteriormente con la Constitución Política de 1991 se abre un marco normativo superior al cual la legislación debe adecuarse. Adicionalmente se han presentado nuevas circunstancias económicas y sociales nacionales e internacionales que hacen necesaria la revisión de la ley."

Para la actualización legislativa, el sector cuenta con la Ley Marco Cooperativa para América Latina preparada por un equipo de expertos para la Alianza Cooperativa Internacional y aprobada en el año 2008 en Costa Rica. Este documento es un referente normativo que tiene en cuenta la nueva realidad económica y propone a los países de la región lineamientos para actualizar sus legislaciones. (Enlace Solidario, 2009)

El acto cooperativo es producto de una organización cooperativa, que viene a ser el sujeto principal de la relación jurídica. Ello trae como consecuencia la configuración de un acto colectivo en donde las manifestaciones de voluntad que concurren en la organización se caracterizan por ser paralelas, buscar el mismo interés, generar una voluntad colectiva y formar una misma parte que propenda por el beneficio común (Estas connotaciones encuadrarían dentro de lo que se conoce como acto subjetivo, en tanto que el acto cooperativo pertenece a la actividad misma de la organización).

Las relaciones jurídicas de las cooperativas tienen como fundamento económico la directriz de señalar a sus bienes y servicios un precio justo, lo más estable posible, que impida la especulación comercial; en ese sentido se predica la ausencia de lucro e intermediación.
Finalmente, afirma su mentor, que el acto cooperativo tiene una naturaleza patrimonial, muy a pesar de que no persigue el lucro sino el interés social, y sin querer esto último significar que sean aquellos denominados como actos gratuitos.

La doctrina argentina, por su parte, advierte en el acto cooperativo la existencia de una serie de elementos que vislumbra como lugares comunes en los textos que abordan el tema, a lo largo y ancho de Latinoamérica:

1. Necesidades individuales comunes;

2. Propósito de obrar en forma conjunta;

3. Solidaridad;

4. Servicios sin fines de lucro (Klug \& Omarini; 1993).

Otros autores incluyen como quinto elemento la búsqueda del bienestar general, el cual debería interpretarse como una consecuencia ineludible del acto cooperativo. Así, por ejemplo tenemos la definición elaborada por el profesor venezolano Jaime Daly Guevara, quien con especial énfasis en la finalidad perseguida, nos refiere el acto cooperativo como la denominación jurídica de un hecho consistente en

\section{"[...] la cooperación entre seres humanos con un fin socioeconómico, es decir, cooperar para procurar el mejoramiento social y económico del grupo mediante la acción conjunta de los miembros de una obra colectiva (Mora; 2004).}

\section{EL ACTO COOPERATIVO EN LA LEGISLACIÓN LATINOAMERICANA}

La teoría del acto cooperativo se recoge con importantes matices y diferencias dentro de las respectivas legislaciones internas de las naciones latinoamericanas. Veamos a continuación en el cuadro algunos ejemplos: 
Tabla No. 1 - Derecho Comparado

\begin{tabular}{|c|c|c|}
\hline PAIS & NORMA & TEXTO \\
\hline ARGENTINA & $\begin{array}{l}\text { Art. 4, D.L. } \\
20.337 / 73\end{array}$ & $\begin{array}{l}\text { Son actos cooperativos los realizados entre las cooperativas y sus asociados } \\
\text { y por aquéllas entre sí en el cumplimiento del objeto social y la consecución } \\
\text { de los fines institucionales. También lo son, respecto de las cooperativas, } \\
\text { los actos jurídicos que con idéntica finalidad realicen con otras personas. }\end{array}$ \\
\hline URUGUAY & $\begin{array}{l}\text { Art. 4, D.L. } \\
15.645 / 84\end{array}$ & $\begin{array}{l}\text { Actos cooperativos son los realizados entre la cooperativa y sus miembros } \\
\text { en cumplimiento del objeto de aquella. Los mismos constituyen negocios } \\
\text { jurídicos específicos cuya función económica es la ayuda mutua, no } \\
\text { considerándose actos de comercio. }\end{array}$ \\
\hline PARAGUAY & $\begin{array}{l}\text { Art. } 8 \\
\text { L. } 438 / 94\end{array}$ & $\begin{array}{l}\text { El acto cooperativo es la actividad solidaria, de ayuda mutua y sin fines de } \\
\text { lucro, de personas que se asocian para satisfacer necesidades comunes o } \\
\text { fomentar el desarrollo. } \\
\text { El primer acto cooperativo es la Asamblea Fundacional y la aprobación del } \\
\text { Estatuto. Son también actos cooperativos los realizados por: } \\
\text { a) Las cooperativas con sus socios; } \\
\text { b) Las cooperativas entre sí; y, } \\
\text { c) Las cooperativas con terceros en cumplimiento de su objeto social. En } \\
\text { este caso se reputa acto mixto, y sólo será acto cooperativo respecto de la } \\
\text { cooperativa. } \\
\text { Los actos cooperativos quedan sometidos a esta ley y subsidiariamente al } \\
\text { derecho común. Las relaciones entre las cooperativas y sus empleados y } \\
\text { obreros se rigen por la legislación laboral. En las cooperativas de trabajo los } \\
\text { socios no tienen relación de dependencia laboral. }\end{array}$ \\
\hline VENEZUELA & $\begin{array}{l}\text { Art. } 7 \text {, Ley de } \\
\text { asociaciones } \\
\text { cooperativas/ } \\
01\end{array}$ & $\begin{array}{l}\text { Son actos cooperativos los realizados entre las cooperativas y sus asociados } \\
\text { o por las cooperativas entre sí o con otros entes en cumplimiento de su } \\
\text { objetivo social y quedan sometidos al derecho cooperativo, y en general al } \\
\text { ordenamiento jurídico vigente. }\end{array}$ \\
\hline COLOMBIA & Art. 7, L. 79/88 & $\begin{array}{l}\text { Son actos cooperativos los realizados entre sí por las cooperativas, o entre éstas y sus } \\
\text { propios asociados, en desarrollo de su objeto social. }\end{array}$ \\
\hline
\end{tabular}

(http://www.esespinal.com/cartillapdf/1_EL_ACTO_COOPERATIVO.pdf) Recuperado el 20 de julio de 2011.

En conclusión después de ver las variadas pero muy similares posiciones de la legislación de los países consultados el acto cooperativo se determina como la relación existente entre asociado y cooperativa que se cumple en cumplimiento del objeto social de las cooperativas.

También se precisa que los asociados se reúnen para lograr fines comunes, por el esfuerzo común y la ayuda mutua.
El cuadro comparativo se podría confundir con sociedades comerciales. Dado que la sociedad comercial como la civil, también tienen una función que favorece los intereses de los socios por lo que se unen para realizar una determinada actividad económica buscando satisfacer intereses personales.

La diferencia entre las entidades de economía solidaria y la sociedad civil o comercial, es que 
ésta tiene por objeto realizar una actividad económica fundamentalmente dirigida a terceros y que genera lucro. Por su parte la organización solidaria busca atender las necesidades de sus propios asociados y sólo excepcionalmente se negocia con terceros, problema el cual se toca en el desarrollo de este estudio.

A pesar de que no existe una fundamentación legal clara a cerca del acto cooperativo no es posible desconocer su diferencia con el acto civil o de comercio.

Lo que la diferencia es que la cooperativa se crea para realizar operaciones de su giro exclusivo para sus asociados, siendo de excepción la realización de negocios sociales con terceros. De esta diferencia puede derivar el interés en el concepto de acto cooperativo.

\section{ANALISIS ESTADÍSTICO}

Análisis estadístico de entidades con mayor número de queja por uso indebido de las prerrogativas dadas por la ley a las entidades solidarias el periodo comprendido entre enero de 2010 a noviembre de 2011.

El objetivo de este análisis es lograr obtener una estadística de los datos sobre las quejas que se han recibido entre 2010 y 2011 por Supersolidaria, para determinar la necesidad de la creación de una norma, Ley o Decreto que defina y de lineamientos sobre el "acto cooperativo" y su aplicación.

El presente análisis consta de dos etapas, la primera de recolección y la segunda de análisis de datos primarios. La misma fue planificada y efectuada con apoyo de las herramientas informáticas del Sistema Orfeo de Supersolidaria.

Nuestro universo de análisis son las quejas atendidas en la Superintendencia de la Economía Solidaria por parte de la Delegatura Para la Supervisión del ahorro y la forma asociativa Solidaria, para su estudio se trabajó con una muestra formada por las quejas recibidas en el periodo comprendido entre enero de 2010 a noviembre de 2011 sobre el universo de las entidades vigiladas. El relevamiento de datos de la $1^{\circ}$ etapa se llevó a cabo entre los días 18-10-11 al 18-11-11, el instrumento para llevar a cabo el análisis fue un sondeo estadístico de quejas por temas frecuentes.

Los datos logrados no deben interpretarse de manera absoluta por lo cambiante de las situaciones investigadas pero sí marcan tendencias muy definidas al momento de su obtención.

\section{Perfil de los datos analizados:}

Tipo de organización: Cooperativas multiactivas e integrales, asociaciones mutuales, cooperativas de aporte y crédito, entre otras.

Tabla No. 2. - Tipo de Organización / Número de organizaciones

\begin{tabular}{|c|c|}
\hline NOMBRE CLASE ACTIVIDAD & $\mathbf{2 0 1 0} \mathbf{- 2 0 1 1}$ \\
\hline AGRICOLA & 387 \\
\hline ASEO MANTENIMIENTO Y RECICLAJE & 70 \\
\hline COMUNICACIONES & 12 \\
\hline CONSUMO (COMERCIO) & 309 \\
\hline EDUCACION & 104 \\
\hline HOTELES, RESTAURANTES, BARES Y SIMILARES & 16 \\
\hline INDUSTRIA & 98 \\
\hline INMOBILIARIAS Y DE ALQUILER & 13 \\
\hline INTERMEDIACION FINANCIERA & 207 \\
\hline MINERIA & 35 \\
\hline
\end{tabular}




\begin{tabular}{|c|c|}
\hline NOMBRE CLASE ACTIVIDAD & $\mathbf{2 0 1 0} \mathbf{- 2 0 1 1}$ \\
\hline OBRAS PUBLICAS & 98 \\
\hline ORGANISMOS DE REPRESENTACIÓN & 34 \\
\hline OTRAS ACTIVIDADES & 2.155 \\
\hline PECUARIA & 17 \\
\hline PESCA & 1 \\
\hline SALUD & 273 \\
\hline SEGUROS & 4 \\
\hline SERVICIOS DE AHORRO Y CRÉDITO & 1.592 \\
\hline SERVICIOS DE CRÉDITO & 428 \\
\hline SERVICIOS FUNERARIOS & 39 \\
\hline SILVICULTURA & 6 \\
\hline TRANSPORTE & 34 \\
\hline TURISMO & 11 \\
\hline VIGILANCIA Y SEGURIDAD & 1 \\
\hline VIVIENDA & 5.960 \\
\hline TOTAL &
\end{tabular}

Fuente: Elaboración propia - Orfeo

Tema de quejas más frecuentes:

Exceptuando a las Cooperativas de trabajo Asociado y el tema de Devolución de aportes que no atañen a nuestro tema del acto Cooperativo aproximadamente el $34 \%$ de las entidades vigiladas otorgan créditos, y son objeto de este análisis dado que en un número muy importante se realiza sin que medie ningún acto cooperativo a personas cuyo vínculo sea simplemente el de cancelar aportes sin que puedan ejercer sus derechos como asociados:

Se han tomado como muestra las entidades que prestan servicios de crédito y de ahorro y crédito.

Se ha realizado un conteo del número de quejas en contra de entidades vigiladas por Supersolidaria lo que arroja:

Tabla No. 3. - Número de quejas por tema recurrente

\begin{tabular}{|l|c|}
\hline $\begin{array}{l}\text { COBRO DE TASAS DE USURA Y DEMÁS IRREGULARIDADES EN EL OTORGAMIENTO DE } \\
\text { CRÉDITOS }\end{array}$ & 2750 \\
\hline RESPUESTA DE LA ENTIDAD A LA CONSULTA O QUEJA & 2681 \\
\hline DEVOLUCIÓN DE APORTES Y AHORROS & 1100 \\
\hline NO PAGO DE COMPENSACIONES Y SEGURIDAD SOCIAL & 1064 \\
\hline $\begin{array}{l}\text { ACTUACIONES IRREGULARES DE DIRECTIVOS, JUNTA DE CONTROL SOCIAL Y REVISOR } \\
\text { FISCAL (ROBO) }\end{array}$ & 1023 \\
\hline OTRAS NO CONTEMPLADAS EN LOS PUNTOS ANTERIORES (ESPECIFICAR) & 868 \\
\hline FALTA DE CONTESTACIÓN A TRÁMITES & 652 \\
\hline SOLICITUD DE INFORMACIÓN & 621 \\
\hline $\begin{array}{l}\text { VIOLACIÓN DE LANATURALEZA JURÍDICA DE LAS ORGANIZACIONES (INTERMEDIACIÓN } \\
\text { LABORAL,SERVICIOS A TERCEROS) }\end{array}$ & 275 \\
\hline
\end{tabular}




\begin{tabular}{|l|c|}
\hline EXCLUSIÓN, TRABAJADORES CESANTES Y RETIROS IRREGULARES DE ASOCIADOS & 211 \\
\hline QUEJOSO RECURRENTE & 182 \\
\hline ASAMBLEAS IRREGULARES & 140 \\
\hline ACUSE DE RECIBO & 125 \\
\hline COBRO INDEBIDO DE CUOTAS DE ADMINISTRACIÓN, SOSTENIMIENTO Y OTROS & 110 \\
\hline RETIRO DE ASOCIADO Y CRUCE DE CUENTAS & 104 \\
\hline DESISTIMIENTO DE QUEJA & 79 \\
\hline $\begin{array}{l}\text { SOLICITUDES SOBRE PROCESOS DE INTERVENCIÓN FORZOSA ADMINISTRATIVA PARA } \\
\text { LIQUIDAR O ADMINISTRAR }\end{array}$ & 74 \\
\hline REPORTE A CENTRALES DE INFORMACIÓN FINANCIERA & 67 \\
\hline EMBARGOS & 48 \\
\hline $\begin{array}{l}\text { RENUENCIA A SUMINISTRAR INFORMACIÓN POR PARTE DE LOS ADMINISTRADORES, } \\
\text { JUNTAS DE CONTROL SOCIAL }\end{array}$ & 37 \\
\hline TRASLADO POR COMPETENCIA & 31 \\
\hline PETICIONES ANÓNIMAS & 22 \\
\hline CANCELACIÓN DE MEDIDAS PREVENTIVAS & 17 \\
\hline ERRORES EN LAS INSCRIPCIONES DE ACTOS & 16 \\
\hline
\end{tabular}

Fuente: Elaboración propia - Orfeo

Se desprende de los datos mencionados que las quejas en su gran mayoría son por temas relacionados con el otorgamiento de créditos de manera irregular, que sumado con los embargos da más del $27 \%$ del gran total de las quejas recibidas en los periodos evaluados.

Llama la atención que la realizando un estudio de lo informado en las peticiones realizadas por los usuarios se pudo evidenciar que estos solo hacen uso de los servicios de crédito de la cooperativa desconociéndose la finalidad de este tipo de organizaciones dado que no gozan de los privilegios como la participación democrática, el derecho a elegir y ser elegido, no reciben capacitación cooperativa, entre otros aspectos que materializan el deber ser de un "acto cooperativo".

Como conclusión de este análisis evidenciamos una desfiguración del modelo Cooperativo protegido por la Constitución Política de Colombia y reglamentado por la Ley 454 de 1998 dado que las personas que acuden por un servicio a las entidades solidaria realmente tienen el carácter de usuarios de créditos más no de asociados dado que no se da esa relación como resultado de la aplicación del artículo 7 de la Ley 79.

Como resultado en primera instancia con esta propuesta se impulsaría a las organizaciones solidarias a mantener un registro social acorde a lo preceptuado en la Circular Básica Contable 004 de 2008, expedida por Supersolidaria, lo cual haría necesaria una actualización con datos totalizados de forma anual por parte de los administradores. Se tendría control sobre la veracidad de la información suministrada por la organización a los entes de control.

Con ello se obligaría a este tipo de empresas a que llevaran actualizado el registro social, brindar el curso obligatorio de economía solidaria, mayor control en la realización de asambleas, en fin, se pretende que con esta herramienta los actos que realicen las cooperativas con sus asociados no solo sean prestar servicios de crédito sino hacer partícipes a esas personas del manejo y del desarrollo a través de actos cooperativos. 
Por último, para garantizar la protección de los derechos de los asociados y la comunidad en general se requiere de una reglamentación que logre unificar y fijar el concepto de acto cooperativo como se verá en el siguiente título.

\section{PROYECTO DE LEY O DECRETO REGLAMENTARIO}

Además de las propuestas y modelos señalados se pretende realizar un proyecto de ley, norma, circular o decreto con el fin de impulsarlo a través de una iniciativa legislativa que de forma general contendría lo siguiente:

\section{"PROYECTO DE LEY NUMERO 280 DE 2011 SENADO}

por la cual se reglamenta al acto cooperativo

El Congreso de Colombia

\section{DECRETA:}

Artículo $1^{\circ}$. Defínase "acto cooperativo", el cual está enunciado en Ley 79 así:

"Artículo $7^{\circ}$. Serán actos cooperativos los realizados entre sí por las cooperativas, o entre éstas y sus propios asociados, en desarrollo de su objeto social.".

Artículo $2^{\circ}$. Adiciónase un párrafo al Artículo $7^{\circ}$. De la Ley 79, así:

"Dichos actos deben implicar el ejercicio de los derechos y deberes en desarrollo de los principios universales cooperativos, como la participación democrática y activa de los asociados.

Artículo $3^{\circ}$. La presente ley rige a partir de su expedición y deroga las disposiciones que le sean contrarias.

(...)

\section{CONCLUSIONES Y RECOMENDACIONES}

Es importante el planteamiento realizado en este trabajo dado que en primera medida hay que señalar lo consagrado en el artículo 58 de la constitución Política de Colombia "El Estado protegerá y promoverá las formas asociativas y solidarias de propiedad", donde el Estado se compromete a velar por el buen funcionamiento de las cooperativas, siendo estas organizaciones entendidas como personas jurídicas que se encuentran en la capacidad para realizar contratos, comparecer en juicio y actuar en todo aquello que esté conforme a su índole social y económico y que conduzca al bienestar común.

Recordemos que desde 1931 con la formalización del modelo solidario en Colombia mediante la Ley 134 hasta la fecha, se han realizado modificaciones para entrar a regular el acto cooperativo y permitir que este cumpla el fin socioeconómico donde todos se encaminen al mejoramiento de este grupo mediante la acción conjunta de los miembros de una obra colectiva.

Realizando el presente estudio se puede evidenciar que en la Superintendencia de Economía Solidaria, entidad creada mediante la Ley 454 de 1998, durante el periodo entre 2010-2011 los temas mas recurrentes de quejas con respecto a su actividad son: Servicios crédito y embargos con un $27 \%$ del total de las quejas recibidas, las cuales en su gran mayoría se relacionan con el otorgamiento de créditos de manera irregular, dando como resultado la desfiguración del modelo cooperativo, el cual se encuentra protegido por la Constitución Política de Colombia y reglamentado en la Ley 454 de 1998.

Se considera entonces en la mayoría de los casos las personas que se dirigen a las cooperativas acuden en búsqueda de un servicio para ser usuarios de créditos mas no en la calidad de asociado como es el deber ser de este tipo de organizaciones implicando para ello la realización de un acto cooperativo el cual es voluntario, igualitario, no lucrativo y sobre todo solidario. 
De lo anterior se desprende el uso indebido que de estas se hace; para contrarrestar esta situación se plantea, en primera medida, una propuesta para impulsar a todas las organizaciones solidarias a mantener un estricto registro social a través de la obligación de diligenciar un formulario u hoja de vida de cada asociado.

Por otro lado se plantea la necesidad de impulsar una ley o decreto reglamentario donde debe primar la participación activa y democrática de los asociados con base a los principios universales del cooperativismo, obligando de esta manera a llevar mayor control de asambleas, brindar cursos de economía solidaria a todos los asociados y que estos a su vez participen activamente del desarrollo de la entidad a través de una participación democrática y efectiva teniendo como base el acto cooperativo.

De esta forma se busca reconocer el espíritu del cooperativismo desde su reglamentación, evitando de esta manera el uso indebido de prerrogativas otorgadas por la ley a entidades de economía solidaria.

Es indispensable tener en cuenta que el acto cooperativo es el núcleo de la ciencia cooperativa, el elemento más importante, su estudio es importantísimo para el conocimiento del fenómeno cooperativo y la actualidad social colombiana por lo que su reglamentación es imperativa.

\section{BIBLIOGRAFÍA}

\section{Libros}

CARDOZO, H. (2006). Auditoria Del Sector Solidario. Aplicación De Normas Internacionales. Colombia: ECOE Ediciones / Colección Textos Universitarios.

JARAMILLO, F., URIBE, R. \& Uribe, C. Conversatorio sobre la "utopía" cooperativa. Fundequidad y La Equidad Seguros, 2005, pp. 17-24.

KLUG, R. \& OMARINI, C. (1993) "Acto cooperativo". En: Derecho cooperativo, tendencias actuales en Latinoamérica y la Comunidad Económica Europea. Colección empresa y tecnología, Bogotá, D.C.: Consultamérica,

MORA, A. (2004) "Carácter no lucrativo de las empresas cooperativas". Documento presentado en la II Convención Cooperativa Regional, Confederación de Cooperativas del Caribe y Centro América, Instituto Salvadoreño de Fomento Cooperativo, San Salvador.

SALINAS, A. (1954) Derecho cooperativo. Doctrina, jurisprudencia, codificación. México: Editorial Cooperativismo.

SARMIENTO, A. \& GUARIN, B. (2003). Aspectos Legales de la Gestión Cooperativa. Colombia: Pontificia Universidad Javeriana.

\section{Revistas}

BEL, P. \& CABALEIRO, M. (2002). La sociedad cooperativa: fórmula empresarial idónea para el desarrollo rural endógeno y sostenible. Revista Española de Estudios Agrosociales y Pesqueros. p. 9-25.

Supersolidaria. (2009) Ley Marco Cooperativa para América Latina. Revista Enlace Solidario.

\section{Normas}

Colombia. Cámara de Representantes. Proyecto de Ley 066/2010.

Colombia. Constitución Política de Colombia. Legis. Bogotá. 2005.

Colombia. Superintendencia de La Economía Solidaria. Circular Externa 007/2001. Ilegalidad de los embargos de pensiones por obligaciones adquiridas por deudores de cooperativas que no son asociados de las mismas.

Colombia. Congreso de la República de Colombia. Ley 454 de 1998, que transformó al Departamento Nacional de Cooperativas -Dancoop- en el Departamento Administrativo de la Economía Solidaria -Dansocial-; y creó a 
la Superintendencia de la Economía Solidaria -Supersolidaria- y al Fondo de Garantías del Sector Cooperativo -Fogacoop.

Colombia. Presidencia De La Republica De Colombia. Decreto ley 2150 de 1995.

Colombia. Congreso de la República de Colombia, Ley 79/1988, página 3, 31.

Colombia. Presidencia De La Republica De Colombia. Decreto 2536 del 4 de agosto del 1986 se adopta el concepto de Economía Solidaria y que dio vida al Consejo Nacional de Economía Solidaria y lo reconoce como un sector de gran importancia en el entorno económico nacional.

Colombia. Presidencia De La Republica De Colombia. Decreto Ley 1598 de 1963.

Colombia. Congreso de la República de Colombia, Ley 141 de 1961, Código Sustantivo del Trabajo.

Colombia. Congreso de la República de Colombia. Ley 134 de 1931.

\section{Jurisprudencia}

Colombia. Corte Constitucional. Sentencia No. C-589/95: COOPERATIVAS - Realizan actos cooperativos y comerciales. Magistrado Ponente: Dr. FABIO MORON DIAZ

\section{WEBGRAFIA}

Sentencia No. C-589/95. Límites en la función social. Comisión Nacional de Televisión, recuperado el 20 de julio de 2011, de: http:// www.cntv.org.co/cntv_bop/basedoc/cc_sc_ nf/1995/c-589_1995.html

Superintendencia de la Economía Solidaria. Conceptos, recuperado el 20 de julio de 2011, de: http://www.docstoc.com/docs/77643726
/16SUPERINTENDENCIA-DE-ECONOMIASOLIDARIA

Superintendencia de la Economía Solidaria. Conceptos, recuperado el 20 de julio de 2011, de: http://es.scribd.com/doc/28742810/ RESENA-HISTORICA

Acto Cooperativo, recuperado el 20 de julio de 2011, de: http://www.unicolombia.edu.co/ index.php?option $=$ com_content\&view $=$ article \&id $=97 \&$ Itemid $=107$

Acto Cooperativo, recuperado el 20 de julio de 2011, de: http://www.esespinal.com/cartillapdf 11_EL_ACTO_COOPERATIVO.pdf

Superintendencia de la Economía Solidaria. Circulares, recuperado el 20 de julio de 2011, de: http://www.supersolidaria.gov.co/data/Circular 2001_no.0007.doc

Acto Cooperativo, recuperado el 20 de julio de 2011, de: http://www.rodriguezavalos.com/ noticias.php?noti_id $=69$

La sociedad cooperativa: fórmula empresarial idónea para el desarrollo rural endógeno y sostenible" en Estudios Agrosociales y Pesqueros, Artículo n. ${ }^{\circ}$ 194, consultado el 19 de julio de 2011, de (http://www.criaderosantarosa.com.ar/ origenesc.htm)

Supersolidaria: 2011 disponible en http://www. supersolidaria.gov.co/nuestra_entidad/resena. php?m=1 Revisado el 19 de julio de 2011.

Supersolidaria:Documento Guía Supersolidaria - Elaboración De Estatutos. Superintendencia de la Economía Solidaria. www.supersolidaria. gov.co

Supersolidaria: Glosario de Economía Solidaria - Supersolidaria, mayo de 2009. www. supersolidaria. gov.co 